\title{
PSYCHOLOGICAL FACTORS INFLUENCING ADJUSTMENT TO RETIREMENT
}

\section{Prof. Ass. Dr. Agron HOXHA}

Heimerer College, agron.hoxha@kolegji-heimerer.eu

\begin{tabular}{ll}
\hline $\begin{array}{l}\text { Article history: } \\
\text { Accepted } 01 \text { October } 2019\end{array}$ & A b s t r a c t \\
Available online 31December 2019 & The quality of aging or life after retirement is determined by levels of psychological well-being and \\
& life satisfaction. The levels of psychological well-being and quality of life satisfaction can be \\
$\begin{array}{l}\text { Keywords: } \\
\text { Aging }\end{array}$ & influenced by multiple factors including personality, perception of individuals about aging and the \\
life satisfaction & quality of respect they get from others. This study was conducted with 170 elderly individuals \\
psychological well-being & ranging from 65 to 85 years of age. The results showed significant relationships between dependent \\
perception & variables such as psychological well-being and life satisfaction, and the independent factors \\
personality and respect. & including personality, perception of aging and respect from others.
\end{tabular}

\section{Introduction}

Today's generations of the world population are becoming older than former generations and projections show that by 2050 older adults (aged 60 or over) will represent about $20 \%$ of the population (Harper, 2014). This demographic phenomenon will pose demanding socio-economic and health challenges to the societies. In order to deal with it, it is of crucial importance to study and understand the needs of older adults and to evaluate what affects their quality of life. Aging is a universal phenomenon but not necessarily in a uniform pattern. Adjustment to retirement represents a developmental phenomenon that must be reconstructed within the context of life-long development.

Generally, older people in are often characterized as being less satisfied and low in psychological well-being. However, no study has been conducted to find out what are the factors that influence their levels of psychological well-being and life satisfaction. Some elderly people think that retirement transition is easy and requires a little planning. However, for some other elderly people retirement is a major life change that, despite the freedom and excitement it offers, also requires personal adjustment to a new life stage (Osborne, 2012; Barrow, 1996). Therefore, the main purpose of this study is to investigate the factors and reasons why people have different views about later life or adjustment to retirement. The proposed factors that could lead elderly people to have different adjustments to retirement were personality, health, social resources, religiosity and socioeconomic status.

People who reported to have higher psychological well-being and good life satisfaction were considered to have good adjustment to retirement (Van Solinge, 2006). Adjustment to retirement refers to the process of getting used to retirement as a new stage of life (Van Solinge, 2006). In the present study, adjustment to retirement refers to life after retirement, which is termed as later life or older age. It is often said that people get sick and die shortly after retirement but, studies do not support this thought (Barrow, 1996).

Retirement alone does not lead to low psychological well-being and low life satisfaction; there are other factors that influence elderly people's adjustment to retirement. Some people adjust well to retirement whereas others have problems adjusting to retirement. One man reported this:

'I turn 80 next February. It's always a milepost, I suppose, but no big deal. I retired about 75 percent at age 65 and then fully retired at age 70. It was easy, very easy, for me to retire. I like the freedom to do what I want, go where I want. I never understood these people who are restless and unhappy in retirement. It seems to me that they have not got much imagination'. (Barrow, 1996: 162). 
People like this man have no problems with adjustment to retirement. However, others do have problems with adjustment to retirement. As mentioned above, there are other factors that influence elderly people having problems with adjustment to retirement. In the below section, the researcher will elaborate on the psychological factors that have significant influence on adjustment to retirement including life satisfaction and psychological well-being.

\section{Psychological Factors Influencing Adjustment To Retirement}

This part intends to present studies related to psychological wellbeing and life satisfaction. Theories of aging and retirement will also be discussed to show how aging and retirement are associated with psychological well-being and life satisfaction. Finally, the conceptual framework of the present study will be presented.

\subsection{Psychological Well-being}

Psychological well-being is a complex term that confuses people about the meaning of the term psychological well-being. Because, generally speaking well-being means feeling physically and mentally healthy and having a good life (Kibret and Tareke, 2017). Well-being of elderly people depends on how positive or negative people's experience is perceived, including feelings of happiness, sadness, anxiety, or excitement (Tinkler \& Hicks, 2011). Many studies have focused on psychological well-being in correlation to older age. Psychological well-being is a variable that has different meaning for different social scientists. However, one definition that would be acceptable for most scientists would be what researchers often term subjective wellbeing. Subjective refers to personal evaluation based on how the person feels about him/herself. Therefore, combining the definition of subjective and well-being would refer to a person who feels physically and mentally healthy about him/herself and not what others would diagnose them. In addition, we can say that subjective well-being and psychological well-being mean the same for most of the time (Barrow, 1996).

Although psychological well-being is important for all age group, it is particularly more relevant to older people for several reasons. It was estimated that in 20 years' time, nearly a quarter of the population in the UK will be aged 65 and over (Medical Research Council, 2010). As life expectancy increases, the issue of maintaining psychological well-being and morale at older ages is becoming more important. Since maintaining is becoming more critical and more important every, it is more effective to divert people's attention to take preventive measures rather than maintaining psychological well-being at older age. It is more important to find out what influences quality of psychological or subjective well-being.

What influences psychological well-being is another issue; for the last 60 years scientists have attempted to find out what decreases psychological well-being in later life. One of the findings by Cagney and Lauderdale (2002) suggested that elderly people with higher levels of education, income and wealth reported higher psychological well-being as compared to elderly individuals with lower levels of education, income and wealth. In addition, psychological well-being was found to be associated with spiritual beliefs and health. It was reported that people who were weak in health (mental and physical health) showed lower levels of psychological well-being. Furthermore, elderly people who were involved in religious activities reported having higher levels of psychological well-being compared to people who were not involved in religious activities (Edison, Boardman, William and Jackson, 2001; Kirby, Coleman and Daley, 2004). There are certain factors like religiosity, social activities and exercises which elderly people could improve in later life, but, there are some other factors that should be considered before feeling old enough. For example, education, knowledge to share, health and many other factors that everyone should consider in advance. There are studies that found psychological well-being lower at older age as compared to younger generation, but these studies were contradicted by other studies (Zaninotto, Falaschetti, and Sacker (2009). It is not the age itself that leads people to lower quality of psychological well-being; there are other factors that influence the quality of well-being. Therefore, it was found that once controlling factors like health, socioeconomic status, and psychological factors, there are no overall cohort differences in quality of life between older adults and younger adults. It is not appropriate to say that as people get older; their quality of life gets lower. Factors that had a negative impact on quality of life over time were depression, functional limitations, poor wealth, not being in paid employment, not perceiving positive support from one's spouse, children and friends, and having a small social network of close friends and family. These factors can have impact on younger generations as well, only those younger generations have more time to make up and improve the quality of those factors. Therefore, the researcher is suggesting that in order to people to have better quality of aging, they must be aware of the factors that have stronger impact on the quality of psychological well-being than the aging itself.

\subsection{Life Satisfaction}

Life satisfaction is one of the strongest criteria for describing the ageing process. Higher levels of life satisfaction in later life predicts higher quality of aging process. In addition, previous researchers have made no difference between life satisfaction and 
quality of life (George and Bearon,1980). Happy elders reported to have higher levels of life satisfaction and quality of life. Life satisfaction can be defined as a sense of satisfaction or pleasure about one's present and past life. One view of successful aging accepted by social gerontologists is the life satisfaction approach which maintains that people have aged successfully is they feel happy and satisfied with their present and past endeavors. According to Eid and Diener (2004) the focus of subjective wellbeing has been to try to explain how people experience their lives, their cognitive assessment, emotional reaction and adjustment to later life. In most cases, life satisfaction is considered to be a cognitive feature of subjective well-being, implying a judgmental process where elderly people perceive their present life situation in comparison to their desired life satisfaction (Krause, 2004).

These findings suggest that it is the cognitive perception of elderly individuals about their later life, it is the expectations they have at the later stage of their life. The challenge for elderly people seams to lie on their life expectations and desired outcomes; therefore, it is suggested that people in general need to be more realistic and understanding about what they expect and desire. Furthermore, in order for people to have a better life satisfaction in later life, they need to prepare themselves in advance. For example, one of the main factors that determines the level of life satisfaction is type of personality. Retirees who reported high in extraversion as compared to introversion, reported higher life satisfaction and were more active during retirement (Osborne, 2012). Extraverts tend to be more outgoing than introverts and thereby tend to make friendships more easily. Although retirees may score higher on introversion, having control over when and how one retired facilitates well-being (Lockenhoff, Terracciano, \& Costa, 2009).

\subsection{Personality and Perception of Aging}

Personality has been noted to be playing an important role across all stages of life. Similarly adaptation in old age is also influenced by biological and social changes. Biological changes may interfere with the brain's functioning. Social changes can lead to isolation or feelings of worthlessness. Hence personality is undeniably very important aspect of in successful ageing. People who feel and perceive themselves with higher self-esteem and are more optimistic are more likely to integrate in social activities and hence experience better psychological well-being (Herero and Extremera, 2010).

There are five types of personality traits that have direct influence on how individuals perceive aging. These five personality traits are openness, conscientiousness, extraversion, agreeableness and neuroticism Johnson and Spinath (2013).
Openness refers to people who are open and motivated to learn new things and enjoy new experiences. People who score high in openness are associated with traits like being insightful and imaginative and having a wide variety of interests.

Conscientiousness on the other hand explains people with higher levels of reliability. People who score high in conscientiousness are reported to be more organized and detailed than people with lower levels of conscientiousness.

Extraversion refers to outgoing people, people that get their energy from interacting with others, while introverts get their energy from within themselves. These people tend to be more energetic, talkative, and assertive as compared to people who score higher in introversion.

Agreeableness explains individuals that tend to be friendly, cooperative, and compassionate. People who score low in levels of agreeableness may be more distant and isolated. People who score high in agreeableness tend to be kinder, affectionate, and more sympathetic than individuals with lower levels of agreeableness are.

Neuroticism refers to degree of negative emotion of individuals. Sometimes, neuroticism is also known as emotional stability. Individuals that score high on neuroticism often experience emotional instability and negative emotions such as being moody and tense.

It is reported that people in general have their own traits of personality and that they cannot change. This study does not intend or suggest for people to change, but awareness about what personality trait is expected to show on certain situations and with certain people is very important. Each individual must be aware of their own personalities and understand the impact that each personality trait can have in relation to quality of life. Therefore, it is very important that individuals understand and acknowledge different styles of personalities' people may have, hence, be aware of what is expected of yourself despite of your actual personality type. For example, you may not be an outgoing person (extrovert), but on certain occasions and with certain people you should go out, even though you happen to be more introvert (not an outgoing person). Because, it is well experimented that people who are more extroverts experience more successful aging than introverted individuals do (Osborne, 2012).

Previous studies indicated that low scores on neuroticism and high scores on extraversion, openness to experience, agreeableness, and conscientiousness are significantly helpful for successful aging. Higher levels of emotional stability, 
agreeableness, and conscientiousness were positively related to higher levels of cognition, higher likelihood of engaging in volunteer work, higher levels of activities of daily living, and higher levels of subjective health. Extraversion and openness to experience were also positively associated with cognition and engaging in volunteer work (Baek, Martin, Siegler, Davey and Poon, 2016).

Some people can be lonely because they lack companionship and not because of their age, and still they may attribute it to the aging process which is actually not true. Sometimes personality affects the perception of aging; some individuals perceive aging as natural, even if they face stressful events. Isaacowitz and Smith (2003) studied 516 participants aged 70 and older in Berlin. This study's main purpose was to find out what predicts positive affect in old age such as happiness, joy and satisfaction in later life on the one hand and negative affect such as distress, fear and anger on the other hand. Personality was found to be a strong predictor of the aging experience; it was even stronger predictor of aging experience than was health (Isaacowitz and Smith, 2003). Individuals who scored high in extraversion were reported to have more positive experiences of aging, whereas individuals who scored high in neuroticism were reported to have more negative experience of aging. Thus, it was concluded that extraversion predicted positive affect and neuroticism predicted negative affect in later life (Isaacowitz and Smith, 2003). Extrovert adults were reported to be less lonely in later life. They were reported to have larger social networks than adults who were not extrovert. Extroverts were warmer and more sociable. Their social network could provide them emotional support even after the death of a spouse or if lacking family interaction (Lang and Martin, 2000).

Older people who had high self-esteem reported having good control and the ability to maintain their health. It was concluded that individuals who evaluated themselves as high in self-esteem were less likely to suffer from chronic illnesses (Bailis and Chipperfield, 2002).

Featherstone and Hepworth (1991) suggested two types of aging images which are distinguishable among elders. The first one is called 'heroes of aging' which refers to elders who have a positive attitude towards aging. They usually take care of themselves and do not act like being old but on the contrary try to be young all the time in their daily actions, bodily posture and general behavior. These people are regarded as optimists in other studies; they perceive aging and stressful events as challenging and not as threats to their life. People like 'heroes of aging' and optimists are more likely to show improvement in psychological well-being and have better physical health. The second image of aging is that some elders experience severe bodily decline through disabling illness to the extent that the outer body is seen as misrepresenting and imprisoning the inner self. This type of image is called 'mask of aging' and shows the more disagreeable aspects of the aging process and a negative attitude towards aging. They perceive aging and the problems that come with aging as threats to their life. These people are more likely to decline in their physical health and life satisfaction (Featherstone and Hepworth, 1991; Uskul and Greenglass, 2005).

As people age, their extrovert personality type declines whereas introvertness increases. They are more likely to stay home and not be involved in usual activities as compared to before when they were younger. Extroverts were more likely to have their own social network, which was reported to help them cope with aging (Field and Millsap, 1991).

\subsection{Respect}

In the words of Kofi Annan, Secretary-General of the United Nations:

"Trees grow strong over the years, rivers wider. Likewise, with age, human beings gain immeasurable depth and breadth of experience and wisdom. That is why older persons should not be only respected and revered: they should be utilized as the rich resource to society that they are." (Powell, 2005).

Before we discuss the value of older people it would be necessary to present some statistics prepared by Simon Powell (2005). The statistics show that the world is getting older because the number of people over the age of 60 will triple over the next 50 years, growing from approximately 600 million to nearly 2 billion. This is due to a combination of factors including a significant decrease of birthrates (below replacement level) and an increase in longevity. Currently, one in every ten persons is 60 years and older; by 2050 , this number will grow to 1 in 5 . At that point, nearly $80 \%$ of the world's older population will be living in less developed regions of the world.

It was suggested that the more compassion and personal vitality young people attributed to elderly people, the older adults would be respected and not avoided. It was also suggested that, higher respect for older people and lower avoidance of older people would be associated with higher life satisfaction. Some studies have shown that the way older people are treated by the younger generation and peers as well can have a significant impact on their reports of life satisfaction and self-esteem (Powell, 2005). Therefore, it is recommended to treat older adults fairly and with dignity regardless of disability or other status, because it was reported that polite talk from young adults can help them by having benefits on psychological well-being. Respecting old 
people the way they expect will help them cope with aging. The purpose of this article was to ensure that older adults are treated fairly and with dignity until the end, to respect them and to fulfill their needs when necessary in all stages of their life (Powell, 2005).

391 older people from six European countries were examined. The participants were aged 60 and older and from a range of educational, social and economic backgrounds. These participants were examined to find out their views on human dignity in their lives in association to self-esteem and well-being. When a person was pain-free, washed, in a clean bed and clothes and had contact with other people, this made him/her feel cared for and well respected. Feeling cared for and respected in later life enhanced the self-esteem, self-worth and well-being of elders. Understanding the dignity of later life, and applying it to older people by respecting their needs and communicating with them enhanced their self-esteem and well-being. In other words old people were more satisfied and had more positive perceptions of aging when they felt cared for and respected by others (Bayer, Tadd and Krajcik, 2005). The way the younger generation or peers responded to the older generation was reported to have a significant impact on life satisfaction and psychological wellbeing in later life. The more politeness young adults showed to older adults, the more benefits elders gained in life satisfaction and psychological well-being. In this way older people reported being more respected and not avoided by their peers and younger generation. It was concluded that politeness and positive communication were associated with life satisfaction and psychological well-being in later life (McCann, Dailey, Giles and Ota, 2005).

\section{Theories: Aging and Adjustment to Retirement}

This section highlights the main theories which explain the psychosocial factors to influence aging and adjustment to retirement.

Regarding life after retirement Havighurst (1986) reported:

"The decrease of interaction proceeds against the desires of most aging men and women. The older person who ages optimally is the person who stays active and who manages to resist the shrinkage of his social world. He maintains the activities of middle age as long as possible and then finds substitutes for work when he is forced to retire and substitutes for friends and loved ones whom he loses by death" (Quadagon, 1999: 161).

Since the 1960s interest in studying the post retirement population in terms of their aging image has increased gradually (Featherstone and Wernick, 1995). The number of professional and scientific journals about gerontology also increased during the last decade. Some of the possible reasons for this increased number of professional journals would be the increasing number of old people, their increased lifespan and the ever-growing burden on society for their care (Rogers, 1986). According to Sarah and Pat (1989) by the late 1960s it was accepted that the normal period of full-time employment would stop for most of the population at the age of 60 or 65 . At these ages most people, especially men, stop working and as a result this created a major crisis of identity. As people age their occupational and physical status changes to the extent that they come to understand that they are no more the prime movers within their family or at work. Parsons (1942) described the problems that retirement brings to people by postulating:

"In view of the very great significance of occupational status and its psychological correlates, retirement leaves the older man in a peculiarly functionless situation, cut off from participation in the most important interests and activities of the society.... Retirement not only cuts the ties of the job itself but also greatly loosens those to the community of residence. It may be surmised that this structural isolation from kinship, occupational and community ties into the fundamental basis of the recent political agitation for help to the old. It is suggested that it is far less the financial hardship of the position of elderly people than their "social isolation" which makes old age a "problem" (Parsons, 1942:616).

Levinson (1980) suggested that after retirement people should learn how to pass their leadership to the younger generation because they cannot be the prime movers in the family or at work anymore. As Levinson (1987) reported, old people should take the "back seat" at their later stage of life and let others lead in the family or work. This process was termed as view from the bridge. Levinson suggested that elderly people should pass their duties and responsibilities to younger generation and learn to agree with younger generation. It is not necessary for them to avoid all of those cares and duties that they had before but they could hand over some of those duties and cares to other family members or younger friends. (Stuart-Hamilton, 1994). Levinson identified four overlapping stages in the life cycle of people with each stage lasting about 25 years and each stage having its own psychological, physical and social issues (Stuart-Hamilton, 1994; and Rogers, 1986). It is the last stage of life which starts at the age of 60 and over, when individuals experience more life distractions. During this time older adults experience higher levels of stress and anxiety because of their physical decline that occurs to them and also because they are labeled as old people after their sixties. In this stage people are recommended to accept the realities of their past, present and future in order to be satisfied 
with their lives. However, if they come to reject these realities, they would be more vulnerable to psychosocial and physical problems (Hayer, Rybash and Roodin, 1999).

Old age is usually referred to the last stage of human life. Erik Erikson proposed eight stages of life span. Each life stage has specific issues which were generalized to all people who go through the stages. The first six stages included the years from birth to young adulthood. The seventh stage includes individuals aged 26 to 50 . This is the stage of generativity versus stagnation, generativity results when individuals try to satisfy their needs by turning towards others such as bearing children and trying to contribute to the younger generation by mentoring and guiding them. However, stagnation results when individuals at this stage do not get satisfaction from others, in other words their contribution to others results in frustration or lack of fulfillment (Quadagon, 1999).

Regarding generativity Levinson (1996) reported:

"Most of us during our forties and fifties become "senior members" in our own particular world. We are responsible not only for our own work but also the development of the current generation of young adults. . . . It is possible in this era to become more maturely creative, more responsible for self and others, more universal in outlook, more capable of intimacy than ever before" (Quadagon, 1996: 20).

The eighth and final stage of life starts from the age of sixty and above. This stage of life encounters the issues of ego integrity versus despair. In later life, Erikson argued that individuals who reached the last stage of their lives are characterized by a psychological conflict between ego integrity and despair. Individuals with ego integrity would appraise their old age and will acquire wisdom, acknowledge the universal nature of humanity and accept the fact of mortality. Here is how Erikson described individual's ego integrity:

"It is a post-narcissistic love of human ego---not of the self---as an experience which conveys some world order and spiritual sense.... It is the acceptance of one's one and only life cycle as something that had to be and that, by necessity, permitted of no substitutions. . . It is a comradeship with the ordering ways of distant times and a different pursuit ... [but] the possessor of integrity is ready to defend the dignity of his own life style against all physical and economic threats. . . Ego integrity, therefore, implies an emotional integration which permits participation by followership as well as acceptance of the responsibilities of leadership" (Belsky, 1990: 268-269).
According to Erikson's theory, the person who has reached ego integrity should be able to accept the past and death (Blesky, 1990). In this stage people get to be more aware of the fact that death for them is approaching. This is the stage when old people look back at what they have done and achieved during their life period. Individuals who perceive that their seven former stages as proposed by Erik Erikson were successfully accomplished, were reported to have had a meaningful and satisfying life, which is ego integrity. However, some other people reported being not satisfied with their life and not having had a meaningful life during the seven former stages. These people were categorized under despair. These people were not happy with their lives, so they blamed themselves for their disappointment, thus despair (Rogers, 1986). Despairing old people may become withdrawn and hesitant or destructive in their old age. Regarding the stage of ego integrity versus despair Erik Erikson (1968) reported:

"A meaningful old age, then... serves the need for that integrated heritage which gives an indispensable perspective on the life cycle. Strength here takes the form of that detached yet active concern with life bounded with death, which we call wisdom. . . To whatever abyss ultimate concerns may lead individual men, man as a psychosocial creature will face, toward the end of his life, a new edition of the new identity crisis which we may state in words, "I am what survives me". (Rogers, 1986: 140--144)

Based on the role theory, the main task for men is their work, and with retirement their main task is finished, so it is this time when disengagement begins (Fennell, Phillipson and Evers, 1988). As individuals age, members of their social network start dropping off one by one. Their neighborhood as well starts disappearing, and as a result old individuals may give up their social or external resources and instead turn themselves towards their inner resources. Older individuals in fact automatically distance themselves from society and external resources. Further, disengagement theorists reported that this disengagement process is universal, normal and natural (Belsky, 1990). Disengagement has been defined as an inevitable process in which many of the relationships between a person and other members of society are severed, and those remaining are altered in quality (Belsky, 1990). According to disengagement theory, retirement is the time for elders to relax and maintain higher morale in old age, in other words disengagement suggests that old people should stop getting involved in their daily activities. Disengagement involves the process of social and psychological withdrawal of an individual from society. Disengagement occurs when "the individual becomes sharply aware of the shortness of life and the scarcity of time remaining to him, and if he perceives his life space as decreasing" (Quadagon, 1999: 215). Disengagement usually leads to reduction of daily activities and ego energy in later life. 
This view has been challenged by the gerontologists whereby they disagreed with disengagement theorists because disengagement theory challenged the traditional view about the importance of maintaining high levels of activity and interaction in old age. The alternate theory that was proposed was the activity theory, which proposes that happiness in later life is to stay as involved in life activities as possible (Belsky, 1990). The contradiction between disengagement and activity theory is that, according to disengagement theory, older adults should be withdrawn from their daily activities and focus on maintaining higher morale and avoid life activities, whereas gerontologists insist that older people should remain active for as long as possible.

In one of the largest studies conducted, the Duke Project involving 250 individuals aged 60 and older. It was concluded that older individuals who reported the highest activity levels scored highest in life satisfaction, contrary to what disengagement theory would predict. Disengagement theory would suggest that in older age people who score high in daily activities would score low in life satisfaction (Quadagon, 1999). Gerontologists suggest that, in order to avoid certain psychosocial and health declines, older adults should continue pursuing their usual life activities and not disengage from them (Fennell, Phillipson and Evers, 1988). Gerontologists suggested that disengagement theory should be rejected because this theory in some way forces people to withdraw from society and life activities in older age which according to activity theory harms the psychosocial and physical health of individuals in later life (Belsky, 1990).

In conclusion, old age was reported to be a very complicated stage whereby older individuals face higher levels of stress, anxiety, depression and health problems as compared to the younger generation. So, they come to face different problems in trying to adjust with those psychosocial and physical problems. Erikson and Levinson proposed theories explaining differences at different stages of the lifespan. Erikson proposed eight stages of life but we focused more on the last stage which is ego integrity versus despair. Ego integrity results when an old person accepts the past and death, whereas despair on the other hand results when an old person is not satisfied with his past and does not want to accept that death is approaching. Different theorists suggested different ideas about adjustment in later life such as disengagement theory suggesting that retired people should decrease their life activities and relax. On the other hand activity theory suggests just the opposite of disengagement theory which is not to withdraw from life activities, but instead keep life as active as possible. Thus, this is both agreement and disagreement on the most appropriate approach to coping with adjustment to retirement.

\section{Methodology}

The main study was conducted in Kosova and focused mainly on elderly individuals. the measures used were those that had been previously validated in the pilot study. The main purpose of the present study was to assess the factors that influenced the retired or elderly people's levels of psychological well-being and life satisfaction.

\subsection{Participants}

In the main study 170 elderly individuals participated. 106 of the participants were males and 64 were female. Participants were randomly selected from different institutions and locations. Participants were aged between 60 to 89 with a mean of 68.7 $(\mathrm{SD}=6.2$ ). The majority (113) of the participants were married, 48 were widowed, 8 were divorced and only one participant had never married. In terms of education, 29 participants were uneducated, 86 had primary school or 8 years of school, 41 had secondary school, 12 of them had completed their first degree and only 2 had second degrees (post graduate). 127 participants were living together with their children, 31 were living with their spouses alone and 12 were living in the institutions.

\subsection{Procedure}

In this study the researcher decided to distribute the questionnaires to participants who could read and understand only in order to avoid the interviewer bias. Surveys were conducted in institutions for the elderly, houses, villages, religious institutions and other random places. Permission to enter the retirement houses in Kosova was taken from the main director of the retirement house in Prizren. This person's permission was recognized in all retirement houses of Kosova.

\subsection{Measures}

In the present study, structured interviews and self-administered questionnaires were utilized to measure the association between symptoms of psychological wellbeing, life satisfaction and participants' personality and perception of aging among elderly people at their post-retirement period.

\section{Psychological Well-being}

The Affect Balance Scale (ABS) is a scale developed by Bradburn (1969) to measure the psychological well-being of the general population. In the ABS 10 items in series was used to ask people about their positive and negative feelings with "yes" or "no" answers. The final psychological well-being scale used for the final study consisted of 7 items. The correlation coefficients of the psychological well-being scale ranged from .23 to .64 with a Cronbach's alpha of .72. 


\section{Life Satisfaction}

The Life Satisfaction Scale (LSS) is an instrument that measures desired and achieved goals of elderly individuals. The LSS was developed by Neugarten, Havighurst and Tobin (1961). These researches had developed three main scales to measure life satisfaction among elderly people aged 50 and above. The final life satisfaction scale used for the final study consisted of 12 items. The correlation coefficients ranged from .30 to .61. The Cronbach's alpha of the life satisfaction scale was .79, which indicates high internal consistency between items.

\section{Personality and Perception of Aging}

The items were combined from different scales related to introvertness and extrovertness (Robinson and Shaver, 1991).The final personality scale used in final study consisted of 8 items. The correlation coefficients of personality scale ranged from .26 to .40 . The perception of aging scale that was used in the final study consisted of 10 items and the correlation coefficients ranged from .27 to .56 . The Cronbach's alpha for the perception scale was .73 which indicates high internal consistency between items.

\section{Religiosity}

This religiosity scale of seven items was developed by the researcher to assess the importance of religious activities and practices in later life. The items were developed based on religious requirements, what is required and what is practiced by them and if the practice helped them adjust with retirement. The items were in question form and the answer was from $0=$ not at all to $10=$ extremely. 1 to 10 response set was used because the greater range of possible answers made it was easier to rate the level of religiosity. For example one of the items was "do you feel that religion gives you spiritual support"?

\section{Results}

The analysis of psychometric properties of the scales revealed that the measures of personality, perception of aging and respect used are reliable and valid instruments. Similarly, the measures used to determine the levels of psychological well-being and life satisfaction among elderly individuals in Kosova were also reliable and valid.

In addition, the results revealed that perception of aging was significantly correlated with psychological well-being and life satisfaction. Similar results were found with regard to the association between personality and psychological well-being and life satisfaction.

Furthermore, the results revealed that respect was significantly correlated to life satisfaction and psychological well-being.

\subsection{The Relationship Between Personality,} Psychological Well-Being and Life Satisfaction

On the relationship between personality and the dependent factors, the findings indicate that there are significant relationships between personality, perception of aging and psychological well-being and life satisfaction. The personality type of the participants was associated with dependent factors. Elderly individuals who were extroverts in personality tended to have better psychological well-being and life satisfaction which was consistent with the study of Isaacowitz and Smith (2003) in Berlin. Extroverts reported having better experience of aging.

Similar relationships were observed between perception of aging and the dependent variables. Individuals who reported having more positive perceptions about aging showed better psychological well-being and life satisfaction which is consistent with studies of personality whereby people who perceived aging and stressful events as challenging and not threats to life were observed to have improvement in psychological well-being and to be more satisfied with their lives (Uskul and Greenglass, 2005). People who showed more positive perceptions about aging in later life reported having better psychological well-being and life satisfaction

\subsection{The Less Respect the Elderly Individuals \\ Get Lower Levels of Life Satisfaction and Psychological Well-Being}

The findings from Pearson correlation revealed that respect is significantly related to the total scale scores on psychological well-being, and life satisfaction. The results reveal that the strongest correlation was observed between respect and life satisfaction, $\quad(r=0.35)$. Psychological well-being showed significant but more moderate association with respect.

\subsection{Regression analysis}

The regression correlation revealed that psychological well-being was significantly measured by the total scale score of personality scale, Beta $=.168, \mathrm{n}=170, \mathrm{p}<.015$. The results reveal that personality measures the level of psychological well-being among elderly people of Kosova.

Overall, the results of regression analysis revealed that $33 \%$ of variance in life satisfaction and $39 \%$ of variance of psychological well-being are explained by the model.

On the other hand, using multiple regression analysis in predicting the power of personality and respect on life satisfaction 
was found that the model explains $33 \%$ of the variance in levels of life satisfaction (R Square $=.329)$.

Life satisfaction was found to be predicted by the personality and the level of respect elderly individuals in Kosova were sharing with others. The regression correlation revealed that life satisfaction was significantly measured by the total scale score of personality scale, Beta $=.174, \mathrm{n}=170, \mathrm{p}<.001$, by the total scale score of perception scale, Beta $=.416, \mathrm{n}=170, \mathrm{p}<.001$ and by the total scale score of respect scale, Beta=.243, $n=170, p<.002$. The results reveal that personality, perception and respect were found to predict the change in the level of life satisfaction among elderly people of Kosova.

\section{Discussions}

The analysis of psychometric properties of the scales revealed that the measures of personality, perception of aging used in this study are reliable and valid instruments.

In addition, the results revealed that perception of aging was significantly correlated with psychological well-being and life satisfaction. Similar results were found with regard to the association between personality and psychological well-being and life satisfaction. Personality was found to be the strongest predictors of the levels of psychological wellbeing. This result indicated that personality does influence the levels of psychological wellbeing which could be supported by Isaacowitz and Smith (2003) who reported that personality is a strong predictor of the aging experience; the more extroverted the person the more positive experiences of aging reported. Similarly, personality and perception of aging were found to be the stronger predictors of life satisfaction. The result indicated that personality and perception of aging predicts the levels of life satisfaction. One explanation could be that personality and perception of aging are interrelated. Personality type of elderly people influences the perception of aging, then perception of aging determines the level of life satisfaction. Extroverted individuals could have more positive perception of aging which in turn is associated with higher life satisfaction.

The findings indicate that there is a strong positive association between respect and life satisfaction indicating that elderly people are more satisfied with their life if they get enough respect from others. In other words, respect in later life plays a very important role for determining the level of life satisfaction. This finding is consistent with a previous study which suggested that the way older people are treated by the younger 132 generations as well as peers can have a significant impact on their reports of life satisfaction and psychological well-being (Powell, 2005). In addition, Bayer, Tadd and Krajcik (2005) reported that elderly people are more satisfied when they feel respected and cared for by others.

\section{Conclusion}

The present study measured the relationship between personality, psychological well-being and life satisfaction in Kosova. The results indicated that type of personality and level of respect have strong influence in adjustment to retirement among elderly people of Kosova. The findings indicated that more attention should be given to elderly people in Kosova because they complained that they are not getting what they need and deserve.

\section{References}

1. Bailis, D. \& Chipperfield, J. (2002) Compensating for losses in perceived personal control over health: A role for collective self-esteem in healthy aging. The Journals of Gerontology, 57b, 6, 531.

2. Barrow, G. M. (1996) Aging, the Individual, and Society. New York, West Publishing Company.

3. Bayer, T., Tadd, W. \& Krajcik, S. (2005a) Quality in Ageing. Health \& Medical, 6, 122

4. Bayer, T., Tadd, W. \& Krajcik, S. (2005b) Dignity: The voce of older people. Quality in Ageing, 22.

5. Belsky, J. K. (1990) The Psychology of Aging. California, Brooks/Cole.

6. Bradburn, N. M. (1969) The structure of psychological well-being. In Robinson, J. R., Shaver, P. R. \& Wrightsman, L. S. (1991) (Eds) Measures of Personality and Social Psychological Attitudes, San Diego: Academic Press.

7. Cagney, K. \& Lauderdale, D. S. (2002) Education, wealth, and cognitive function in

8. later life. The Journals of Gerontology, 57b, 2, 163.

9. Edison, C., Boardman, J., Williams, D. \& Jackson, J. (2001) Religious involvement, stress, and mental health: Findings from the 1995 Detroit area study. Social Forces. 80, 1, 251.

10. Eid M, Diener E. (2004) Global judgments of subjective well-being: Situational variability and long-term stability. Social Indicators Research. 65(3):245-277.

11. Featherstone, M and Wernick, A. (1995). Images of Aging. London: Routledge.

12. Featherstone, M., \& Hepworth, M. (1991). The mask of ageing and the postmodern life course. In Featherstone, M and Wernick, A. (1995). Images of Aging. London: Routledge. 
13. Field, D. \& Millsap, R. (1991) Personality in advanced old age: Continuity or Change? Journal of Gerontology. 3, 299.

14. George and Bearon (1980) in Krause, N. (2004) Lifetime trauma, emotional support, and life satisfaction among older adults. The Gerontologist, $44,5,615$.

15. Harper, S. (2014). Economic and social implications of aging societies. Science, 346, 587-591

16. Havighurst (1986) in Quadagon, J. (1999) Aging and the Life Course: An Introduction to Social Gerontology. USA, McGraw-Hill.

17. Hayer, W. J., Rybash, J. M. \& Roodin, P. M. (1999) Adult Development and Aging. New York: McGrawHill.

18. Herero. V. G. and Extremera, N. (2010) Daily life activities as mediators of the relationship between personality variables and subjective well-being among older adults. Personality and Individual Differences 49, 124-129

19. Isaacowitz, D. \& Smith, J. (2003) Positive and negative affect in very old age. The Journal of Gerontology, 58b, 3, 143.

20. Jik Joen Lee (2005) An exploratory study on the quality of life of older Chinese people living alone in Hong Kong. Social Indicators Research, 71 335-361

21. Kibret BT, Tareke G (2017) The Contribution of Instructor, Peer and University Support for Promoting Psychological Well-Being among Students in the Amhara Regional Universities. Clin Exp Psychol 3: 154.

22. Kirby, S., Coleman, P. \& Daley, D. (2004) Spirituality and well-being in frail and nonfrail older adults. The Journals of Gerontology 59b, 3, 123.

23. Krause, N. (2004) Lifetime trauma, emotional support, and life satisfaction among older adults. The Gerontologist, 44, 5, 615.

24. Krause, N. (2005) Stressor arising in highly valued roles, meaning in life, and the physical health status of older adults. The Journals of Gerontology, 59b, 5, 287.

25. Levinson $(1980,1987)$ in Stuart-Stuart-Hamilton, I. (1994) The Personality of Aging. London and Bristol, Jessica Kingsley Publishers.

26. Lockenhoff, C. E., Terracciano, A., \& Costa, P. T. (2009). Five-factor model of personality traits and the retirement transition: Longitudinal and cross-sectional associations. Psychology and Aging, 24(3), 722-728

27. Long, M V. and Martin, P. (2000) Personality, relationship closeness, and loneliness of oldest old adults and their children. The Journals of Gerontology, 311.

28. McCann, R., Dailey, R., Giles, H. \& Ota, H. (2005) Beliefs about intergenerational communication across the lifespan: Middle age and the roles of age stereotyping and respect norms. Communication Studies, 56, 4, 293.

29. Neugarten, B. L., Havighurts, R. J. \& Tobin, S. (1961) The measurement of life satisfaction. In Robinson, J. R., Shaver, P. R. \& Wrightsman, L. S. (1991) (Eds) Measures of Personality and Social Psychological Attitudes, San Diego: Academic Press.

30. Osborne, J.W. (2012) Psychological Effects of the Transition to Retirement. Canadian Journal of Counselling and Psychotherapy, Vol. 46, 1, 45-58

31. Parsons (1942) in Featherstone, M and Wernick, A. (1995). Images of Aging. London: Routledge.

32. Powell, S. (2005) The World Assembled on Aging,

33. http//www.stridemagazine.com/articles/. Accessed on 23/6/20017.

34. Robinson, J. R., Shaver, P. R. \& Wrightsman, L. S. (1991) (Eds) Measures of Personality and Social Psychological Attitudes, San Diego: Academic Press.

35. Rogers, D. (1986) An Introduction to Aging. New York: Prentice Hall.

36. Sarah, H. and Pat, Th. (1989) The consolidation of "old age" as a phase of life, 1945-1965, in Featherstone, M and Wernick, A. (1995). Images of Aging. London: Routledge.

37. Stuart-Stuart-Hamilton, I. (1994) The Personality of Aging. London and Bristol, Jessica Kingsley Publishers.

38. Tinkler L., Hicks S. (2011). Measuring subjective well-being. London: Office for National Statistics.

39. Uskul, A. K. \& Greenglass, E. (2005) Anxiety, stress, and coping. psychological well-being in Turkish Canadian sample. Stress Anxiety and Coping. 18, 3, $269-278$

40. Van Solinge, H. (2006). Adjustment to and satisfaction with retirement. Journal of Gerontology:Social Sciences. 60, 1, 11.

41. Zaninotto P, Falaschetti E, Sacker A. (2009) Age trajectories of quality of life among older adults: results from the English Longitudinal Study of Ageing. Quality Life Research;18(10):1301-9. 